\title{
UJI MUTU MINYAK GORENG SAWIT KEMASAN X DAN Y BERDASARKAN STANDAR NASIONAL INDONESIA (SNI)
}

\author{
Quality Test of Palm Cooking Oil Packaging X and Y \\ Based on Indonesian National Standard (SNI)
}

\author{
Syafrinal \\ Politeknik ATI Padang \\ * rinal1450@gmail.com
}

\begin{abstract}
Packaged palm cooking oil is one of the basic needs of the community which is consumed almost every day which is sold in packaged form. It is very important for us to know the quality of the packaged palm cooking oil that we consume so that our health can be maintained. This study aims to test the quality of packaged palm cooking oil $X$ and $Y$ based on the Indonesian National Standard (SNI) and determine better quality of packaged palm cooking oil. The parameters of the test are Free Fatty Acid (FFA), Moisture \& Impurities ( $M \&$ I), Iodine Value (IV), Peroxide Value (PV), and Color. The results showed that the test parameter values for packaged palm cooking oil $X$ and $Y$ were $0.072 \%$ and $0.073 \%$ for FFA. $M$ \& I content were $0.043 \%$ and $0.046 \%$. The IV value was $60.837 \mathrm{~g} \mathrm{I} / 100 \mathrm{mg}$ oil and $59.023 \mathrm{~g} \mathrm{I2} \mathrm{/} 100 \mathrm{mg}$ oil. The $\mathrm{PV}$ values were $0.098 \mathrm{Mek} \mathrm{O} 2 / \mathrm{Kg}$ and $0.102 \mathrm{Mek} \mathrm{O2/Kg}$. Colour values are 2.5/51 red/yellow and 2.0/51 red/yellow. All test parameters carried out were in accordance with SNI except for the yellow colour test and obtained palm cooking oil packaging $X$ was better in quality than $Y$.
\end{abstract}

Keywords : packaged palm cooking oil, free fatty acid (FFA), moisture \& impurities (M \& I), iodine value (IV), peroxide value (PV)

\begin{abstract}
ABSTRAK
Minyak goreng sawit kemasan merupakan salah satu kebutuhan pokok masyarakat yang dikonsumsi hampir setiap hari yang dijual dalam bentuk kemasan. Sangat penting bagi kita untuk mengetahui mutu dari minyak goreng sawit kemasan yang kita komsumsi agar kesehatan tubuh bisa tetap terjaga. Penelitian ini bertujuan untuk menguji mutu minyak goreng sawit kemasan X dan $\mathrm{Y}$ berdasarkan persyaratan Standar Nasional Indonesia (SNI) dan menentukan mutu minyak goreng sawit kemasan yang lebih baik. Parameter uji yang dilakukan adalah uji Free Fatty Acid (FFA), Moisture \& Impurities (M \& I), Iodine Value (IV), Peroxide Value (PV), dan Colour. Hasil penelitian menunjukan bahwa nilai parameter uji dari minyak goreng
\end{abstract}


sawit kemasan X dan Y secara berturut - turut adalah 0,072\% dan 0,073\% untuk kadar FFA. Kadar M \& I sebesar 0,043\% dan 0,046 \%. Nilai IV sebesar 60,837 g I / $100 \mathrm{mg}$ minyak dan 59,023 $\mathrm{g} \mathrm{I}_{2} / 100 \mathrm{mg}$ minyak. Nilai PV sebesar 0,098 $\mathrm{Mek} \mathrm{O}_{2} / \mathrm{Kg}$ dan 0,102 Mek $\mathrm{O}_{2} / \mathrm{Kg}$. Nilai Colour sebesar 2,5/51 Merah/Kuning dan 2,0/51 Merah/Kuning. Semua parameter uji yang dilakukan telah sesuai dengan SNI kecuali uji Colour warna kuning dan diperoleh minyak goreng sawit kemasan X lebih baik mutunya daripada Y.

Kata Kunci: minyak goreng sawit kemasan, free fatty acid (FFA), moisture \& impurities (M \& I), iodine value (IV), peroxide value (PV)

Submit: 16 Oktober $2021 *$ Revisi: 26 Oktober $2021 *$ Accepted: 2 November $2021 *$ Publish: 18 November 2021

\section{PENDAHULUAN}

Minyak Goreng Sawit adalah bahan pangan dengan komposisi utama trigliserida berasal dari minyak kelapa sawit (RBDPO), yang telah melalui proses fraksinasi, dengan atau tanpa penambahan bahan pangan lain dan bahan tambahan pangan, dan mengandung vitamin A dan/atau provitamin A [1]. Minyak goreng sawit kemasan merupakan salah satu kebutuhan pokok masyarakat yang dikonsumsi hampir setiap hari yang dijual dalam bentuk kemasan. Sangat penting bagi kita untuk mengetahui mutu dari minyak goreng sawit kemasan yang kita komsumsi agar kesehatan tubuh bisa tetap terjaga [2]. Banyak jenis minyak goreng sawit kemasan yang beredar di Indonesia, dua diantaranya adalah merk $\mathrm{X}$ dan $\mathrm{Y}$.

Mutu minyak goreng sawit kemasan $\mathrm{X}$ dan $\mathrm{Y}$ dikatakan baik jika memiliki sedikit kandungan air dan kotoran, karena air dapat menghidrolisis minyak menghasilkan asam-asam lemak bebas yang menyebabkan bau tengik pada minyak sehingga tidak layak untuk dikomsumsi karena akan membuat gatal di tenggorokan. Kandungan air dan kotoran pada minyak goreng sawit dapat ditentukan dengan menghitung kadar Moisture \& Impurities (M \& I) sedangkan kandungan asam lemak bebas dapat ditentukan dengan menghitung kadar Free Fatty Acid (FFA). Menurut [1] kadar $\mathrm{M} \&$ I dalam minyak goreng sawit adalah kecil dari 0,1\% dan kadar FFA kecil dari $0,3 \%$.

Mutu minyak goreng sawit juga dapat ditentukan dari komponen asam lemak penyusunnya, yakni golongan asam lemak jenuh atau tidak jenuh. Asam lemak tidak jenuh mengandung ikatan rangkap. Sebaliknya, asam lemak jenuh tidak mempunyai ikatan rangkap [3]. Semakin banyak ikatan rangkap, maka semakin bagus mutu minyak goreng sawitnya karena asam lemak yang memiliki banyak ikatan rangkap akan semakin reaktif terhadap oksigen sehingga cenderung mudah teroksidasi. Derajat ketidakjenuhan dari minyak goreng sawit dapat ditentukan dengan menghitung nilai Iodine Value (IV) dan menentukan derajat kerusakan minyak goreng sawit akibat oksidasi dapat ditentukan dengan menghitung nilai Peroxide Value (PV). Menurut [1] nilai IV dalam minyak goreng sawit sebesar 45 $-46 \mathrm{~g} \mathrm{I}_{2} / 100 \mathrm{mg}$. 
Mutu dari minyak goreng sawit selain dilihat dari kandungan kimiawinya, juga dapat dilihat dari pengujian secara fisika dengan melihat kenampakan fisik atau karakteristik. Minyak goreng sawit tidak boleh berbau dan beraroma netral. Warna minyak goreng merah orange atau kuning biasanya dapat disebabkan adanya pigmen karetonoid yang larut dalam minyak tersebut yang dapat diukur dengan menguji colour [4].

Penentuan mutu minyak goreng sawit dapat didasarkan pada Standar Nasional Indonesia (SNI). Standar SNI merupakan standar yang digunakan untuk mendasari penetapan mutu dari suatu produk yang umum digunakan di Indonesia. Berdasarkan latar belakang di atas peneliti melakukan penelitian untuk menguji mutu minyak goreng kemasan $\mathrm{X}$ dan Y berdasarkan beberapa parameter uji yaitu Free Fatty Acid (FFA), Moisture \& Impurities (M \& I), Iodine Value (IV), Peroxide Value (PV), dan Colour.

\section{METODOLOGI PENELITIAN}

\section{Bahan dan Alat}

Bahan yang digunakan untuk penelitian ini adalah minyak goreng kemasan $\mathrm{X}$ dan $\mathrm{Y}$ yang beredar di Kota Padang, alkohol netral, indikator PP, larutan $\mathrm{NaOH} 0,01 \mathrm{~N}$, siklo heksana, larutan wijs, larutan KI $10 \%$, akuades, Larutan $\mathrm{Na}_{2} \mathrm{~S}_{2} \mathrm{O}_{3} 0,1 \mathrm{~N}$, indikator starch, asam asetat, kloroform, KI.

Alat yang digunakan untuk penelitian ini adalah penelitian ini adalah neraca analitik, gelas piala, oven, erlenmeyer, buret, lovibond PX995.

\section{Metode Penelitian}

Prosedur penelitian

\section{Uji Moisture \& Impurities (M \& I)}

Ditimbang dua gelas piala kosong pada neraca analitik dan dicatat (berat A), kemudian masing - masingnya dimasukkan sampel minyak goreng sawit kemasan X dan Y sebanyak 15 gram (berat B). Kedua sampel dimasukkan dalam oven dengan suhu $130^{\circ} \mathrm{C}$ selama 2 jam kemudian didinginkan pada suhu kamar Setelah dingin ditimbang kembali (berat $\mathrm{C}$ ).

$$
\% \mathrm{M} \& \mathrm{I}=\frac{(\text { Berat }(\mathrm{A}+\mathrm{B})-\text { Berat } \mathrm{C}) \times 100 \%}{\text { Berat } \mathrm{B}}
$$

\section{Uji Free Fatty Acid (FFA)}

Sampel minyak goreng sawit kemasan $\mathrm{X}$ dan $\mathrm{Y}$ ditimbang pada neraca analitik sebanyak $15 \mathrm{~g}$ yang dimasukan ke dalam 2 erlenmeyer berbeda, ditambahkan masingmasingnya $50 \mathrm{~mL}$ alkohol netral dan dipanaskan hingga mendidih. Ditambahkan indikator PP dan dititrasi dengan $\mathrm{NaOH} 0,01 \mathrm{~N}$ sampai muncul warna merah muda dan tidak hilang lagi saat diaduk. Dicatat volume $\mathrm{NaOH}$ yang terpakai.

$\% \mathrm{FFA}=\frac{\text { Volume } \mathrm{NaOH} \times \mathrm{N} \mathrm{NaOH} \times 25,6}{\text { berat sampel }}$

\section{Uji IV}

Ditimbang 0,5 g minyak goreng sawit kemasan $\mathrm{X}$ dan $\mathrm{Y}$ di erlenmeyer pada neraca analitik dan ditambahkan masing-masingnya $20 \mathrm{~mL}$ siklo heksana dan $25 \mathrm{~mL}$ larutan wijs, kemudian didiamkan 30 menit dalam ruangan gelap dan tertutup. 
Ditambahkan 20 mL larutan KI $10 \%$ dan $100 \mathrm{~mL}$ akuades, dititrasi dengan $\mathrm{Na}_{2} \mathrm{~S}_{2} \mathrm{O}_{3} \quad 0,1 \mathrm{~N}$ hingga warna kuning gading dan ditambahkan 3 tetes indikator starch (kanji) kemudian dititrasi lagi dengan $\mathrm{Na}_{2} \mathrm{~S}_{2} \mathrm{O}_{3} \quad 0,1 \mathrm{~N}$ hingga warna biru tepat hilang. Dicatat volume $\mathrm{Na}_{2} \mathrm{~S}_{2} \mathrm{O}_{3}$ yang terpakai

$\mathrm{IV}=\frac{\left(\text { vol blanko }- \text { vol pentiter) } \mathrm{x} 12,69 \times \mathrm{N} \mathrm{Na}_{2} \mathrm{~S}_{2} \mathrm{O}_{3}\right.}{\text { berat sampel }}$

\section{Uji PV}

Sampel minyak goreng sawit kemasan $\mathrm{X}$ dan $\mathrm{Y}$ ditimbang sebanyak $5 \mathrm{~g}$ di erlenmeyer pada neraca analitik dan masing-masingnya ditambahkan 30 $\mathrm{mL}$ campuran asam asetat dan kloroform dengan perbandingan 3:2, dikocok 1 menit. Ditambahkan $1 \mathrm{~mL}$ $\mathrm{KI}$ jenuh dan $30 \mathrm{~mL}$ akuades, dikocok 1 menit dan dimasukan $1 \mathrm{~mL}$ indikator kanji dan segera dititrasi dengan $\mathrm{Na}_{2} \mathrm{~S}_{2} \mathrm{O}_{3} \quad 0,01 \quad \mathrm{~N}$ hingga larutan berubah warna dari biru sampai dengan warna biru mulai menghilang. Dicatat volume $\mathrm{Na}_{2} \mathrm{~S}_{2} \mathrm{O}_{3}$ yang terpakai.

$$
\mathrm{PV}=\frac{\text { Volume pentiter } \times 1000 \times \mathrm{N} \mathrm{Na}_{2} \mathrm{~S}_{2} \mathrm{O}_{3}}{\text { berat sampel }}
$$

\section{Uji Colour}

Sampel minyak goreng sawit kemasan $\mathrm{X}$ dan $\mathrm{Y}$ dipanaskan diatas hot plate hingga suhu $60{ }^{\circ} \mathrm{C}$. Dihidupkan alat lovibond PX995 dan dizero-kan dengan tekan tombol "ZERO" pada alat. Dimasukkan sampel minyak kedalam kuvet dan diletakan ke dalam alat. Ditekan tombol "READ" pada alat sampai nilai yang didapatkan stabil. Dicatat nilai yang terbaca pada alat.

\section{HASIL DAN PEMBAHASAN}

Hasil pengujian Free Fatty Acid (FFA), Moisture \& Impurities (M\&I), Iodine Value (IV), Peroxide Value (PV), dan Colour, terhadap minyak goreng sawit kemasan $X$ dan $Y$ serta perbandingannya dengan SNI Indonesia ditunjukan pada Tabel 1.

Tabel 1. Hasil Pengujian M \& I, FFA, IV, PV dan Colour terhadap Minyak Goreng Sawit Kemasan X dan Y serta Perbandingannya dengan SNI

\begin{tabular}{|c|c|c|c|}
\hline \multirow[t]{2}{*}{ Parameter Uji } & \multicolumn{2}{|c|}{$\begin{array}{c}\text { Minyak Goreng Sawit } \\
\text { Kemasan }\end{array}$} & \multirow[t]{2}{*}{ SNI } \\
\hline & $\mathrm{X}$ & $\mathrm{Y}$ & \\
\hline $\mathrm{M} \& \mathrm{I} *(\%)$ & 0,043 & 0,046 & $<0,1$ \\
\hline FFA $*(\%)$ & 0,072 & 0,073 & $<0,3$ \\
\hline IV ** ( $\mathrm{g} \mathrm{I}_{2} / 100 \mathrm{mg}$ minyak) & 60,837 & 59,023 & $45-46$ \\
\hline $\mathrm{PV}^{*}(\mathrm{Mek} \mathrm{O} / \mathrm{Kg}) /$ & 0,098 & 0,102 & $<10$ \\
\hline Colour *** (Merah / Kuning) & $2,5 / 51$ & $2,0 / 51$ & $<5,0 / 50$ \\
\hline $\begin{array}{rc}\text { Keterangan: } & \text { SNI 7709-2019 } \\
* * & \text { SNI 3741-1995 } \\
* * * & \text { SNI 7709-2012 }\end{array}$ & & & \\
\hline
\end{tabular}

\section{Uji M \& I}

Kadar M \& I merupakan jumlah air dan kotoran yang terkandung dalam minyak goreng yang menentukan mutu minyak. Semakin rendah kadar M \& I, maka kualitas minyak goreng sawit tersebut semakin baik. Hal ini 
dikarenakan adanya air dalam minyak dapat memicu reaksi hidrolisis yang menyebabkan penurunan mutu minyak [5]. Minyak goreng sawit dengan kadar M \& I yang tinggi jika dipanaskan maka akan menimbulkan percikan minyak saat menggoreng.

Prinsip dari pengujian ini adalah gravimetri penguapan yaitu dengan cara menguapkan air dan kotoran yang terkandung dalam minyak goreng sawit kemasan dengan memasukannya dalam oven selama 2 jam pada suhu $130{ }^{\circ} \mathrm{C}$. Setelah itu didinginkan dan dihitung kembali massa minyak goreng sawit kemasan setelah kandungan air dan kotorannya hilang.

Dari hasil pengujian pada Tabel 1 dapat diketahui bahwa minyak goreng kemasan X mempunyai kadar M \& I (\%) yang lebih rendah daripada minyak goreng kemasan $\mathrm{Y}$ sehingga kualitas minyak goreng kemasan $\mathrm{X}$ lebih baik daripada $\mathrm{Y}$ dan kedua minyak goreng kemasan tersebut telah sesuai dengan SNI 7709-2019. Perbedaan kadar M \& I kedua minyak goreng sawit kemasan ini dapat disebabkan oleh proses pembuahan sawit yang berbeda dan sewaktu panen masih banyak mengandung air dan kotoran.

\section{Uji FFA}

Dari hasil pengujian pada Tabel 1 menunjukan bahwa minyak goreng kemasan X mempunyai kadar FFA yang lebih rendah daripada minyak goreng kemasan Y. Kadar FFA merupakan salah satu indikator mutu dari minyak, semakin tinggi kadar FFA pada minyak maka kualitas dari minyak tersebut semakin buruk [6]. Semakin tinggi nilai FFA, maka minyak akan mengalami kerusakan akibat hidrolisa yang jika dikonsumsi akan membuat gatal di tenggorokan. Tingginya nilai FFA juga dapat disebabkan karena kadar M \& I yang tinggi sehingga mempercepat reaksi hidrolisis dari minyak goreng sawit tersebut. Jadi ada hubungan antara kadar M \& I dengan kadar FFA pada minyak goreng.

Prinsip dari pengujian ini adalah titrasi alkalimetri karena menggunakan larutan standar basa untuk mengetahui kadar FFA dalam minyak. Minyak terlebih dahulu ditambahkan dengan alkohol netral dengan tujuan agar minyak dapat larut sehingga mudah untuk dititrasi.

Dari data tersebut menunjukan kualitas minyak goreng kemasan X lebih baik daripada Y jika dilihat dari kadar FFA. Kadar FFA kedua minyak goreng kemasan tersebut telah sesuai dengan SNI 7709-2019. Perbedaan kadar FFA minyak goreng kemasan $\mathrm{X}$ dan $\mathrm{Y}$ bisa disebabkan oleh perbedaan kadar M \& I nya karena kadar M \& I yang tinggi pada proses produksi dapat meningkatkan kadar FFA.

\section{Uji IV}

Pengujian IV bertujuan untuk mengetahui seberapa besar derajat ketidakjenuhan dari minyak goreng sawit. Semakin tinggi nilai IV maka minyak goreng sawit tersebut semakin tidak jenuh sehingga akan terlihat jernih dan tidak beku, begitu sebaliknya semakin rendah nilai IV maka minyak goreng sawit tersebut akan terlihat keruh terutama pada suhu rendah [7].

Prinsip dari pengujian ini adalah titrasi iodometri dimana penentuan nilai IV nya menggunakan metode wijs. Asam lemak tidak jenuh dalam minyak goreng sawit kemasan ini mampu menyerap iod dan membentuk ikatan jenuh. Jumlah iod yang diserap oleh minyak goreng sawit kemasan inilah yang menunjukan banyaknya ikatan rangkap. Semakin banyak jumlah iod yang diserap 
menunjukan minyak tersebut mengandung ikatan lemak tak jenuh yang banyak sehingga kualitasnya semakin bagus.

Dari data pengujian nilai IV yang ditunjukan pada Tabel 1 dapat diketahui bahwa kualitas minyak goreng sawit kemasan X lebih baik daripada Y dan dapat disimpulkan kedua minyak goreng kemasan tersebut telah sesuai dengan SNI 3741-1995 sebesar 45 - $46 \mathrm{~g} \mathrm{I}_{2} / 100 \mathrm{mg}$. Perbedaan nilai IV kedua minyak goreng sawit kemasan ini disebabkan oleh perbedaan jumlah ikatan rangkapnya dimana jumlah ikatan rangkap minyak goreng sawit kemasan $\mathrm{X}$ lebih banyak daripada Y.

\section{Uji PV}

Nilai PV menunjukan tingkat kerusakan minyak karena oksidasi dan dapat digunakan untuk mengetahui kadar ketengikan minyak. Ketengikan minyak adalah salah satu indikator kualitas minyak goreng sawit kemasan. Minyak goreng yang telah berbau tengik akan menyebabkan minyak menjadi kental, berwarna gelap, dan berbuih yang dapat menyebabkan konsumen yang mengkomsumsinya akan mengalami iritasi pada saluran pencernaan dan tenggorokan, bahkan akibat paling fatal dari ketengikan minyak adalah keracunan dan dalam jangka panjang akan mengakibatkan kanker [8]. Jadi semakin tinggi nilai PV maka kualitas minyak goreng sawit kemasan akan semakin jelek.

Prinsip dari pengujian nilai PV ini adalah titrasi iodometri. Masing-masing minyak goreng sawit kemasan ditambahkan dengan campuran asam asetat yang bersifat polar yang dapat mengekstrak senyawa peroksida yang terdapat pada minyak goreng sawit kemasan dan kloroform yang bersifat non polar yang melarutkan minyak goreng sawit kemasan tersebut. Senyawa peroksida yang terdapat dalam minyak goreng sawit kemasan akan bereaksi dengan KI yang ditambahkan dan membebaskan senyawa Iodin. Iodin yang telah terbentuk ditambahkan dengan indikator kanji dan dititrasi dengan larutan $\mathrm{Na}_{2} \mathrm{~S}_{2} \mathrm{O}_{3}$ hingga warna biru hilang. Jumlah iodin yang bereaksi dengan $\mathrm{Na}_{2} \mathrm{~S}_{2} \mathrm{O}_{3}$ sama dengan jumlah ikatan peroksida yang terdapat dalam minyak goreng sawit kemasan yang diputus oleh Kalium Iodida.

Pada Tabel 1 terlihat bahwa nilai PV minyak goreng sawit kemasan Y lebih tinggi daripada $\mathrm{X}$. Ini menunjukan bahwa minyak goreng sawit kemasan $\mathrm{X}$ lebih baik daripada Y dan nilai PV keduanya telah sesuai dengan SNI 7709-2019. Perbedaan nilai PV minyak goreng kemasan X dan Y bisa disebabkan oleh tingkat oksidasi pada masing-masing minyak tak jenuh nya yang disebabkan oleh udara dan pemanasan.

\section{Uji Colour}

Tujuan pengujian colour adalah untuk mengetahui warna yang terdapat pada minyak goreng sawit kemasan $X$ dan Y. Menurut [1] syarat warna dari minyak goreng adalah merah dan kuning yaitu kecil dari 5 untuk merah dan kecil dari 50 untuk kuning. Warna minyak goreng merah atau kuning disebabkan adanya pigmen karetonoid yang larut dalam minyak tersebut.

Pengujian colour ini menggunakan alat lovibond PX995. Sampel minyak goreng sawit kemasan $X$ dan $Y$ dimasukkan kedalam kuvet dan diletakan ke dalam alat lovibond PX995. Pada alat tersebut terbaca data bahwa warna merah pada minyak goreng sawit kemasan $X$ dan $\mathrm{Y}$ adalah 2,5 dan 2,0 sedangkan 
warna kuning pada kedua minyak goreng sawit kemasan itu adalah 51.

Dari data pengujian colour yang ditunjukan pada Tabel 1 diketahui bahwa kedua minyak goreng sawit kemasan tersebut memenuhi SNI 7709-2019 untuk warna merah dan tidak memenuhi untuk warna kuning. Minyak goreng kemasan yang kualitasnya baik adalah berwarna kuning dan jernih. Warna kuning pada minyak goreng sawit menunjukan adanya beta karoten (pro Vitamin A) yang baik untuk tubuh.

\section{KESIMPULAN}

\section{Kesimpulan}

Dari hasil penelitian yang dilakukan dapat disimpulkan bahwa minyak goreng sawit kemasan $\mathrm{X}$ dan $\mathrm{Y}$ telah memenuhi standar SNI untuk parameter uji Free Fatty Acid (FFA), Moisture \& Impurities (M \& I), Iodine Value (IV), Peroxide Value (PV), dan Colour warna merah kecuali uji Colour warna kuning. Kualitas minyak goreng sawit kemasan tersebut akan semakin bagus jika kadar FFA, M \& I, dan nilai PV nya semakin kecil dan nilai IV nya semakin tinggi serta berwarna kuning jernih. Dari pengujian tersebut diperoleh minyak goreng sawit kemasan $\mathrm{X}$ lebih baik mutunya daripada Y.

\section{Saran}

Untuk penelitian selanjutnya disarankan untuk melakukan pengujian bilangan asam, bilangan penyabunan, indeks bias dan cemaran logam pada minyak goreng sawit kemasan $\mathrm{X}$ dan $\mathrm{Y}$.

\section{DAFTAR PUSTAKA}

[1] BSN, SNI 7709-2019 (Standar Mutu Minyak Goreng). 2019, Badan Standarisasi Nasional: Jakarta.

[2] Lempang, I.R., Fatimawali, and N.C. Pelealu, Uji Kualitas Minyak Goreng Curah dan Minyak Goreng Kemasan di Manado. Jurnal Ilmiah Farmasi, 2016. 5(4): p. 155-161.

[3] Ketaren, S., Pengantar Teknologi Minyak dan Lemak Pangan. 1986, Jakarta: UI Press.

[4] Fitriyono, A., et al., Aplikasi Pengolahan Pangan. 2014, Yogyakarta: Deepublish.

[5] Sumarna, D. Studi Metode Pengolahan Minyak Sawit Merah (Red Palm Oil) dari Crude Palm Oil (CPO). in Seminar Nasional Kimia. 2014. Samarinda: Prosiding.

[6] Yulianto, Analisis Quality Control Mutu Minyak Kelapa Sawit di PT. Perkebunan Lembah Bhakti Aceh Singkil. Amina, 2019. 1(2): p. 7278.

[7] Silalahi, R.L.R., D.P. Sari, and I.A. Dewi, Pengujian Free Fatty Acid (FFA) dan Colour untuk Mengendalikan Mutu Minyak Goreng Produksi PT. XYZ. Jurnal Teknologi dan Manajemen Agroindustri, 2017. 6(1): p. 41-50.

[8] Nainggaolan, et al., Uji Kelayakan Minyak Goreng Curah dan Kemasan yang Digunakan Menggoreng Secara Berulang. Jurnal Pendidikan Kimia, 2016. 8(1): p. 45-57. 